Arab World English Journal (AWEJ) Volume 12. Number3 September 2021

DOI: https://dx.doi.org/10.24093/awej/vol12no3.5

\title{
Assessing Reflection as a Tool of Female Teacher's Professional Development in Saudi EFL Post-Observation Conferences
}

\author{
Farah Nasser Algraini \\ Department of English Language \\ College of Humanities and Sciences at Hotat Sudair \\ Majmaah University, Al-Majmaah, Saudi Arabia \\ Email: f.algraini@mu.edu.sa
}

Received: $2 / 22 / 202$

Accepted: 7/19/2021

Published: 9/24/2021

\section{Abstract}

This qualitative study investigated the effect of Saudi EFL post-observation conferences on female teachers' professional development through assessing teachers' reflection. It also examined to what extent these conferences are considered reflection-enhancing. Moreover, it contributed towards filling the gap in the literature regarding this area because of two reasons. The first is that there is a paucity of research on functional and thematic analyses of postobservation conferences either internationally or in the Arab world. The second is that most studies conducted in this area have only been surveyed. The sample consisted of 30 Saudi EFL female participants divided into 10 supervisors and 20 teachers. They voluntarily recorded the post-observation conferences conducted by them in Saudi schools in Riyadh region. Two analytic systems are used to analyze the recordings: a functional analytic system and a thematic one. The findings showed that post-observation conferences do not contribute towards enhancing teachers' reflective skills as a key element of teachers' professional development.

Keywords: Functional and thematic analyses, reflection, Saudi EFL post-observation conferences, supervision, teacher's professional development

Cite as: Algraini, F. N. (2021). Assessing Reflection as a Tool of Female Teacher's Professional Development in Saudi EFL Post-Observation Conferences. Arab World English Journal, 12 (3) 66 -81. DOI: https://dx.doi.org/10.24093/awej/vol12no3.5 


\section{Introduction}

The supervision process plays a significant role in creating more effective learning environments that develop teachers' performance through determining their strengths and weaknesses and, as a result, developing students' learning outcomes (Aldaihani, 2017). Dickson (2011) asserted that supervision boosts the teaching-learning process, creates favorable learning environments, and encourages collaboration and coordination improving the educational outcomes. He, additionally, indicated that the supervisory process contributes to teachers' professional development, enhances the quality of learning and teaching, recognizes good and bad traits in teachers' practices, and provides support and help to new teachers and teachers who are less competent to be more competent.

Most supervisory visits include three stages, which are a pre-observation conference, a classroom observation, and finally, a post-observation conference (POC). In the first stage, what will happen in the upcoming lesson should be discussed by both teachers and supervisors (Pawlas \& Olivia, 2008). In the second stage, supervisors use an observation form to be filled during visiting teachers' classes. In the post-observation conference, teachers and supervisors meet to discuss general issues related to teachers' teaching practices and particular events recorded during the second stage in the classroom (Vásquez, 2004). In other words, this final stage aims to review and reflect upon data collected during the classroom observation. This plays a vital role in making future plans for professional development opportunities (Zepeda, 2012).

In Saudi Arabia, to the researcher's best knowledge, there have been only a few studies related to post-observation conferences. They have only investigated the perceptions of teachers and supervisors towards the supervisory practices in school settings. Therefore, this research adds to the body of knowledge through two kinds of the analysis of post-observation conferences held by EFL (English as a Foreign language) supervisors and teachers in Saudi school settings. The first is a functional analytic system as the functions implemented by supervisors in such conferences have been analyzed to demonstrate the reflective functional moves produced by them. The second is a thematic analysis that determines the thematic categories and the reflective examples of those themes uttered by supervisors. This aims to investigate to what extent these supervisory meetings foster teachers' reflective practices, and, accordingly, increase their professional development.

This research contributes towards filling the gap in the literature regarding this area because of two reasons. The first is that there is a paucity of research on functional and thematic analyses of post-observation conferences either internationally or in the Arab world. The second is that most studies conducted in this area have only been surveyed. Therefore, the results of this study may:

- Encourage EFL supervisors since they are directed to examine teachers' work to be engaged in successful post-observation conferences.

- Provide Saudi educators who are interested in supervision conferences with the current literature that is related to a new aspect that has never been investigated in Saudi Arabia. As a result, to guide this research, the following questions have been addressed:

- What are the common functions implemented by Saudi EFL supervisors in postobservation conferences? 
- What are the major themes used by Saudi EFL supervisors in the intended discourse of teacher-supervisor post-observation conferences?

- How far do post-observation conferences foster Saudi EFL teachers' reflection?

\section{Literature Review}

\section{The Effect of Supervision on Teacher's Professional Development}

Researchers are different in their perceptions, comprehension, and orientations of the supervision framework. Thus, they have not agreed on a precise definition of this term. For example, it is defined as "a democratic, strategic, resourceful, and coordinating process during which supervisors and teachers come together to stimulate discussions and suggestions, provoke reflective thoughts and weed out deficiencies in the educational setting" (Hismanoglu \& Hismanoglu, 2010, p. 20). It is, additionally, defined as an ongoing process of teacher education in which the supervisor observes the teacher's practices in the classroom focusing on the goal of improved instruction (Gebhard,1990). Beach and Reinhartz (2000) indicated that it is a complicated process that requires working with teachers supporting the collegiality and collaboration in order to develop the quality of teaching and learning within schools. From the definitions mentioned above, supervision can be defined as an ongoing, complex, and consultative process of providing feedback and guidance that aims to improve instruction and enhance teachers' development and, as a result, to promote the quality of teaching and learning through observation and discussion within collegial and collaborative environments.

However, supervision and evaluation are, sometimes, used interchangeably in the literature. While both are crucial, they have separate but complementary functions, and they both have different features. The purpose of these two processes is not always the same. Supervision is a formative process that leads to enhance the growth of teachers and assess their professional development needs (Eady \& Zepeda, 2007). On the other hand, the evaluation of teachers represents an organizational duty providing an overall formal assessment of the competence and performance of teachers (Coimbra, 2013). The aim of evaluation is to prove rather than to improve. In other words, checklists and ratings prove that teachers meet a particular standard with little or no regard to their professional development (Tracy, 1995). Evaluation ensures that the performance of each teacher identifies his/her competence level. The evaluator's duties depend on objectives and targets that are set based on specific pedagogical frameworks (Coimbra, 2013).

Effective professional growth plays a role in changing their teaching philosophy. Kutsyuruba (2003) defined Teacher's Professional Development (TPD) as a basic component of continuous teacher education that is concerned with developing the instructional methods used by teachers and improving teachers' abilities to adapt instruction to meet their students' needs as well as their skills concerning how to manage their classrooms. Moreover, Hismanoglu (2010) stated that it is "an ongoing learning process in which teachers primarily aim at how to teach in accordance with the expectations and needs of the students" (p. 990). The relationship of supervision and teacher's professional growth cannot be underestimated (Beach \& Reinhartz, 2000). Understanding the way of how teachers learn helps supervisors to make plans for direct assistance, in-service education, developing the curriculum, group development, and action research at a suitable level to encourage professional development and improvement of instruction (Mandell, 2006). However, it has been suggested that professional growth cannot be 
separated from reflection, which is considered a bottom-up approach to teachers' professional development (Farrell, 2007). This helps teachers to better solve their problems, use alternative strategies, and be aware of their students' needs (Shotte, 2008).

\section{Reflection}

In teaching, most people misunderstand and criticize the term reflection for being ambiguous (Alrumaih, 2016). This misunderstanding is because of the difference of the perspectives towards teaching, learning, and schooling among those who adopt this concept. ElOkda (2008) defined it as "an ongoing, enquiry-based process involving teachers' commitment, either individually or collaboratively, to explore teaching, learning and all aspects of the teaching-learning context; and to uncover the tacit beliefs, assumptions and values underlying their teaching practices" (p. 2). Reflection is a bottom-up approach to teacher's professional development. This approach is based on the belief that both novice and experienced teachers can better understand their own teaching practices through conscious and systematic reflecting on their teaching experiences. That is, teachers' beliefs about teaching and learning must be critically examined by articulating their beliefs and comparing them to their actual classroom practices to investigate whether there is any contradiction between their practices and such underlying beliefs (Farrell, 2007).

\section{The Significance of Reflection as a Tool of Teacher's Professional Development}

Reflection is said to be beneficial for TPD as it causes teachers to pay attention to some aspects of their teaching practices to enhance them (Al-Abri, 2011). It has been argued that being more experienced alone does not help to learn, accordingly, reflection on experience is significant (Loughran, 2002). Engaging in reflective practices helps teachers to deeply understand their teaching actions, evaluate their professional development, enhance their decision-making skills, and become proactive and confident in their teaching (Feiman-Namser \& Floden, 1986). It has been proven that reflection has an influence on professional development programs as well as on teachers as professional practitioners. (Alanazi, 2016). It has been indicated that reflection makes teachers able to act independently. They become capable of selfcontrolling over their professional tasks. With the help of reflection, autonomous teachers can recognize all political, social, and other ideological factors that are embedded in educational settings. (Bengtsson, 1995). In line with this, Alanazi (2016) stated that reflection enables teachers to be professional and develop their teaching and classroom practices. In other words, teachers can review and investigate what they have implemented in the classroom, carry out changes in practices, and then review and investigate again alternative or enhanced actions.

Reflective practices greatly encourage the professional development of teachers. Susoy (2015) conducted a study that emphasizes the benefits gained by the pre-service teachers from watching their own teaching videos. This enabled them to assess themselves depending on such recorded videos. This practice increased their awareness of events which they could not identify in the classroom. Another study conducted by Abednia, Hovassapian, Teimournezhad and Ganbari (2013) on using journal writing as a reflective practice revealed that there have been several advantages of using a journal in making reflections since it enhances self-awareness, develops personal understanding, constructs reflection and reasons skills, and integrates into conversations with supervisors. 
In the supervision context, teachers need to be reflective practitioners by providing them with convenient tools to promote their own professional practices. The post-observation conference is considered the best context for supervisor-teacher interactions. That is, by discussing the observed lesson, the teacher, and the supervisor can analyze the teacher's performance, and he/she should actively participate in the reflective process (Orland-Barak \& Klein, 2005). Gwyn-Paquette (2001) collected data by recording the interactions that occurred between supervisors and teachers at a secondary school level. He aimed to help teachers to develop their understanding of cooperative learning to be carried out in their classes. The findings showed that the supervisors played a basic role in supporting prospective teachers in problem-solving, reflective practices and the discussion of theoretical principles. In addition, Waring (2013) analyzed video-recorded post-observation conferences between a course instructor and four graduate practicum students in an MA TESOL program in the US. He stated that the supervisor's skills supported the idea that more direct interventionist skills can be conducive to reflection. He highlighted how assessment and advice can foster reflection indirectly because his sample did not explicitly integrate in reflective practices but, rather, he managed to do that.

Arikan (2004) claimed that teacher observation is significant because of gathering information that can be used for teachers' formative and summative assessment. The formative one is emphasized over the summative one if the main concern is to enhance teachers' performance. The information is utilized to provide necessary feedback to teachers to develop their teaching practices. This feedback usually occurs during post-observation conference. To improve reflection through the post-observation conference, the supervisor should not ask a lot of frequent questions because this will make the teacher feels as if he/she is being interrogated. An opportunity should be provided to the teacher to freely reflect upon the observed lesson, with the supervisor's help through occasional probing questions or comments (Al-Abri, 2011). Reflection in the Saudi Context

To the researcher's best knowledge, a few studies have been conducted on reflection among Saudi teachers. For example, Sibahi (2015) investigated EFL teachers' attitudes towards reflective teaching as a tool for professional growth of teachers, and the challenges related to the higher education in Saudi Arabia. She used semi-structured interviews with four EFL Saudi college instructors. The results showed that the participants were aware of the value of the reflective practices. However, some of them mentioned some uncertainties regarding reflection and some limitations impeding reflective teaching in Saudi Arabia. She emphasized the essential need of providing in-service teachers with professional training on reflective teaching.

In line with this, Shukri (2014) explored the perceptions of EFL Saudi teachers towards reflective skills as a tool for developing teachers professionally and the challenges regarding this aspect in the higher education in the Saudi context. She focused on raising teachers' awareness of the importance of teachers' professional development and its influence on meeting their students' needs. She used a structured questionnaire as a quantitative methodology followed by a qualitative analysis of the results. The findings showed a strong relationship between reflective teaching and professionalism in teaching. Furthermore, Almazrawi (2014) investigated the reflective skills and attitudes of Saudi female in-service teachers. She used a survey and individual interviews. The data analyzed revealed that those participants had weaknesses in their 
reflective teaching skills and attitudes. However, she suggested that it is better to enable teachers to modify the curriculum and to enhance their own teaching styles.

\section{Methods}

To investigate to what extent post-observation conferences held by Saudi EFL female supervisors in Riyadh region contribute to female teachers' professional growth through assessing teachers' reflection, a qualitative approach was mainly adopted.

\section{Participants}

The sample consisted of 30 Saudi EFL female participants (10 supervisors and 20 teachers) who were selected randomly. The supervisors voluntarily recorded the POCs with different teachers in Saudi schools at different levels in the academic year 2018/2019 in Riyadh region. This resulted in 20 recordings. For ethical purposes, each supervisor was awarded a code from $A$ to $J$ and each teacher and transcription of the recordings were given a serial number from one to 20 .

\section{Research Instruments}

This study used two analytic systems to analyze the recordings of the POCs held by Saudi EFL supervisors and teachers. The first was a functional analytic system as the functions implemented by supervisors in those conferences were analyzed to demonstrate the reflective functional moves produced by them. The second was a thematic analysis that determined the thematic categories and the reflective examples of those themes used by supervisors in the intended discourse of the teacher-supervisor POCs. Each meeting that occurred between the supervisors and the teachers was recorded and transcribed. After that, the two analytic systems were used to analyze those transcribed recordings. The analytic systems stem from two resources. The first is what has been developed by El-Okda (1997). The second resource is AlAbri's (2011) modified version of El-Okda's (2008) system.

\section{Functional Analytic System}

This study has adopted three main functions from El-Okda's (1997) study, which are Describe, Direct, and Evaluate, and added another function which is Elicit from Al-Abri's (2011) study. The supervisors' sub-functions are classified under each main function as follows (El-Okda, 1997; Al-Abri, 2011):

Describe. It includes:

- Describing an observed practice.

- Describing a practical reason of an observed practice.

- Describing consequences of an observed practice.

- Relating reasons to language teaching principles.

Direct. It includes:

- Directing teachers to act in a specific way.

- Proposing an alternative practice to an observed practice.

- Presenting the rationale for or explain the advice or suggestion provided.

Evaluate. It involves:

- Evaluating whether an observed practice is appropriate or not.

- Clarifying a judgment or opinion. 
- Using some expressions such as excellent or good job and some thanking expressions that are related to evaluative comments only.

Elicit. It includes:

- Eliciting a description of an observed practice.

- Eliciting a practical reason of an observed practice.

- Eliciting what has possibly resulted from an observed practice.

- Eliciting beliefs underlying an observed practice.

- Eliciting some alternative practices to an observed practice.

- Eliciting some consequences of alternatives.

- Eliciting the evaluation of an observed practice.

- Eliciting linguistic knowledge such as spelling and pronunciation.

- Eliciting pedagogical knowledge.

- Eliciting the lesson's objectives.

- Eliciting a summary of the whole of discussion or even some points of what has been discussed.

- Eliciting an agreement of teachers on some points.

- Eliciting clarification.

According to Al-Abri (2011), when the supervisor describes, directs, or evaluates during the POC, it is not necessary that he/she helps the teacher to critically think. To enhance teacher's reflection, the supervisor should ask the teacher to state the practical reason for an observed practice, uncover his/her tacit belief that underlies the practical reason, discuss the results of an observed practice, and elicit an alternative to an observed practice as well as its consequences. Therefore, the moves of elicitation used by the supervisor can be classified into Reflectionenhancing and Non-reflection enhancing moves. It is possible to distinguish those types of moves as Reflection-enhancing moves require the teacher to think deeply and analyze their teaching practices critically while Non-reflection-enhancing moves require teachers just to recall their actions occurred in the classroom. Thus, Elicit move can be divided into two moves as follows:

Reflection-enhancing elicit. It includes:

(1) Elicit a practical reason for an observed practice

(2) Elicit results of an observed practice

(3) Elicit beliefs underlying an observed practice

(4) Elicit an alternative to an observed practice

(5) Elicit consequences of an alternative practice

(6) Elicit evaluation of an observed practice

Non-reflection-enhancing elicit. It involves:

(1) Elicit a description of an observed practice

(2) Elicit linguistic knowledge

(3) Elicit pedagogical knowledge

(4) Elicit lesson's objectives

(5) Elicit a summary of a discussion

(6) Elicit an agreement of the teacher 
(7) Elicit clarification

Thematic Analytic System

The research is mainly based on five categories. They are (Al-Abri, 2011):

Planning and preparation

This includes planning for the whole semester, how to manage the classroom time, how to plan for lessons and units, the aims and objectives of the semester, units and lessons, and the instructional materials used

\section{Lesson delivery and classroom performance}

This involves describing the classroom procedure, the pace of the lessons, warm-up activities, how effective the techniques used are, the assumptions/beliefs underlying the use of specific techniques, techniques used for questioning, and language proficiency.

Classroom management issues

These include issues such as class control, instructions, seating arrangements, nomination techniques, interaction patterns, and talk time for both teachers and students taking into consideration individual differences and reinforcement.

\section{Continuous assessment}

This is related to several issues such as the continuous and formal assessment of student performance and progress provided by teachers, gaining benefits from the information on students' assessment for the purposes of planning and preparation, correcting the written work, and maintaining students' portfolios.

\section{Other administrative issues}

These cover various issues such as absence issues, meetings held in the departments, collaboration with colleagues, contributions to workshops, and peer observation.

\section{Procedure}

1. Before the implementation of the study, a permission to conduct the research was taken from the Saudi Ministry of Education.

2. The anonymity and confidentiality of the participants' identities have been ensured and the consent was given by them.

3. The post-observation conferences that occurred between the supervisors and the teachers were recorded to be systematically analyzed in terms of their functional and thematic categories.

4. The data was collected.

5. The data was then analyzed.

6. Recommendations and suggestions were provided depending on the findings obtained.

\section{Results}

\section{Functional Data Analysis}

Quantitative Analysis of the Functional Data

According to the data, the total number of the main functional categories is 1776 . The most frequent function that occurs in the recordings is Evaluate appearing 451 times and constituting $25.4 \%$. It is very close to the category Direct, which appears in 445 instances representing $25.1 \%$. It is followed by the category Non-reflection-enhancing elicit which occurs in 421 utterances representing 23.7\%. The next main function which is found in 341 examples constituting $19.2 \%$ is Describe. Reflection-enhancing elicit is the least frequent one as it appears in only 118 utterances and represents $6.6 \%$. 
Reflection-enhancing elicit move is closely looked at since the aim of the present study is to investigate the number of the reflective moves in the POCs. The total number of these moves is 118 distributed among six sub-functions. The most frequent sub-functional move under the main function Reflection-enhancing elicit is Elicit a practical reason for an observed practice. It appears 44 times representing $37.3 \%$ of the total number of such moves in this category. It is followed by Elicit beliefs underlying an observed practice, which occurs in 23 instances constituting 19.5\%. Coming third is Elicit an alternative to an observed practice appearing in 21 examples and making a percentage of $17.8 \%$. The next move is Elicit the evaluation of an observed practice with a total number of 14 and so $11.8 \%$. Elicit results of an observed practice comes fifth and it happens 10 times constituting 8.5\%. The least frequent sub-functional move is Elicit consequences of an alternative practice with six frequencies representing $5.1 \%$. Qualitative Analysis of the Functional Data

\section{Evaluate}

It is the most frequent category among the five main functions. According to the recordings, the nature of the most discussions are evaluative. The data reveals that the supervisors tend to directly evaluate the teachers. These evaluative comments do not foster teachers' reflection even if they are positive. In addition, the data indicates that the supervisors pay great attention to stating the teachers' strengths and weaknesses and evaluating the teachers' performance because they are required to prepare evaluative reports on the teachers. However, it is supposed that supervisors should give teachers opportunities to self-evaluate their own teaching practices because this would help to enhance their reflection. The supervisors' practices are judgmental and non-reflective.

\section{Direct}

It is the second main function in terms of frequency. The findings show that, in the most cases, the supervisors provide the teachers with advisory comments as they want teachers to follow their instructions. The supervisors only tend to direct the teachers to change their practices and follow what the supervisors say.

\section{Non-reflection-enhancing elicit}

It is the third most frequent main function. It does not require the teacher to think critically. Most of the time, in this study, the supervisors either ask the teachers to describe how they carry out particular practices or ask them to clarify something. Most of the examples collected show that the supervisors follow the teachers' answers by giving them a piece of advice or an evaluative comment. They do not attempt to ask questions that promote the teachers to think critically, such as 'how can the strategy you used contribute to developing your students and making them more active in the class?'. This kind of questions helps teachers to deeply think and, accordingly, enhance their reflection.

\section{Describe}

It is the fourth main function in terms of frequency. In this category, the supervisors are the ones who describe an observed practice, a practical reason for an observed practice, and consequences of an observed practice. However, supervisors should give teachers opportunities to elicit a description of a certain observed behavior because this requires teachers to think 
critically. As a result, this enhances their reflection which is considered an important component of their professional development.

\section{Reflection-enhancing elicit}

It is what this research is mainly concerned with. This is the least frequent category among the other main functions. The most frequent sub-functional move belonging to this category is Elicit a practical reason for an observed practice appearing in 44 examples with $37.3 \%$ of the total number of this category. The next sub-function that frequently occurs is Elicit beliefs underlying an observed practice with 23 instances and 19.5\%. It is followed by Elicit an alternative to an observed practice appearing 21 times and constituting 17.8\%. The fourth place goes to Elicit evaluation of an observed practice as it represents $11.8 \%$ with only 14 examples. The two least frequent moves are Elicit results of an observed practice and Elicit consequences of an alternative practice with only 10 and 6 instances $(8.5 \%$ and $5.1 \%)$ respectively.

\section{Thematic Data Analysis}

\section{Quantitative Analysis of the Thematic Data}

The frequencies of the thematic categories vary among the 20 post-observation conferences. According to the data, the total number of these categories is 865 . The total number of the category Lesson delivery and classroom performance is 467 constituting $54.8 \%$ of the categories total number. It is the most frequent theme that occurs in the recorded meetings. The second category is Planning and preparation which appears in 269 instances representing $31.2 \%$. This is followed by the category Classroom management which occurs in 85 utterances representing 9.8\%. The next theme which appears in 28 utterances and constitutes $3.2 \%$ is Continuous assessment. The theme Administrative issues is the least frequent one as it appears in only 16 utterances representing $1.8 \%$.

The utterances produced by the supervisors are analyzed twice, as functions and as themes. As mentioned earlier, the functional moves are 1776 moves and the thematic moves are 865 moves. However, some functional moves do not match any of the five themes mentioned above. The functional moves that are classified as reflection-enhancing are 118 out of 1776 . Out of these 118 moves, only 77 moves match specific themes representing $8.9 \%$ of the total number of the whole moves.

The total number of reflective instances related to the category Lesson delivery and classroom performance is 43 constituting 55.8\%, followed by Planning and preparation which appears in 21 examples making 27.8\%. Coming after these two themes is the category Classroom management with 11 reflective instances representing 14.3\%. The last theme is Continuous assessment, which has only two examples representing just $2.7 \%$ of the total number of reflective instances. Regarding the theme Administrative issues, there are no reflective utterances at all.

\section{Qualitative Analysis of the thematic Data}

Analyzing the recorded conferences reveals that 865 thematic moves are used in those conferences. What this study is concerned with is how much the reflection is involved in each theme to investigate the effect of the supervisory process on teachers' professional development throughout reflective moves. The data shows that the reflective instances vary from one theme to 
another. It clarifies that the main focus of the supervisors during such conferences is on Lesson delivery and classroom performance. Regarding this theme, the supervisors talk about the practices performed inside the classroom. Those practices include classroom procedure, the delivery method, warm-up activities, the strategies followed, techniques used for questioning, and language proficiency. This theme appears 467 times, but only 43 instances are considered reflective moves.

In addition, the findings show that the second concern of the supervisors is Planning and preparation. They come across issues related to planning for lessons, the aims and objectives of the units, and the instructional materials used. They do not pay much attention to unit planners or the objectives of the semester. Also, they do not ask about how those objectives are related to the specific or general objectives of the observed lessons or the units. This theme appears in 269 instances and only 21 are considered reflective moves.

As for Classroom management, the supervisors concentrate only on instructions, seating arrangements, time of talking for both the teachers and the students and reinforcing the students. Regarding this category, the focus of some supervisors is on that some teachers do not give the students enough time to participate and express themselves as they are often taking the role of talking. Moreover, the instruction is mainly taken into consideration. Some of the supervisors comment a lot on how the teachers instructed the students.

The supervisors are not often found to be focusing on issues related to Continuous assessment. Regarding this theme, they spend most of their time talking about how the strategies used can impact on the students' performance. Furthermore, some of the supervisors ask the teachers to evaluate their lessons and provide them with advisory comments on what they should do in the future to improve their practices. The least frequent theme is 'Administrative Issues'. It occurs in only 16 utterances. There are no examples of reflective moves. The supervisors only express their opinions about some issues, such as the absence issues and the contributions to workshops.

In summary, the findings emphasize that there are few reflective moves identified throughout the analysis of the data. Furthermore, the results show how the supervisors spend most of the time talking more than the teachers. They do not give the teachers opportunities to think critically and reflect on their practices. They are talking about what happen in the classroom, commenting on the teachers' practices, and advising the teachers to avoid specific behaviors and perform others. Thus, it can be concluded that most of the POCs cannot be considered reflection-enhancing in the Saudi schools. This may be due to the fact that each supervisor should attend 60 classes during the whole school year. In each semester, the supervisor must observe 30 teachers twice: a diagnostic visit and a technical visit. In the diagnostic visit, the supervisor checks the students' performance and investigate whether they have developed. The result of this test should be based on the result of the previous test conducted by the supervisor herself. It should also be supported by the test carried out by the principal of the school. The supervisor examines the results and identifies the teacher's level of development. In the technical visit, after attending the class, the supervisor and the teacher discuss the lesson observed and what happens in that lesson. The supervisor may demonstrate the strengths and weaknesses of the teacher's performance. Thus, there are no opportunities for 
supervisors to guide teachers through the steps of reflection. Therefore, it cannot be said that most of the POCs contribute towards teacher's professional development through fostering teacher's reflection.

\section{Amount of the Supervisors' Talk}

The findings clarify that there is a variety regarding the total number of the words uttered in the 20 recordings of the POCs. This study is concerned with the supervisors' talks, which varies as well. In addition, the analyzed data reveals that the supervisors are talking more than the teachers (over 50\%). This imbalance is not considered a feature of a successful reflective conversation (Al-Abri, 2011). Table one shows the amount of the supervisors' talk that is related to the reflection-enhancing function.

Table1. The amount of talk done by the supervisors

\begin{tabular}{|l|l|l|l|l|l|l|}
\hline $\begin{array}{l}\text { The total } \\
\text { number of } \\
\text { the uttered } \\
\text { words }\end{array}$ & $\begin{array}{l}\text { Supervisors' } \\
\text { talk }\end{array}$ & $\begin{array}{l}\text { Teachers' } \\
\text { talk }\end{array}$ & $\begin{array}{l}\text { Supervisors' } \\
\text { talk } \\
\%\end{array}$ & $\begin{array}{l}\text { Teachers' } \\
\text { talk } \\
\%\end{array}$ & $\begin{array}{l}\text { The total } \\
\text { number of } \\
\text { supervisors' } \\
\text { reflective } \\
\text { words }\end{array}$ & $\begin{array}{l}\text { Supervisors' } \\
\text { reflective } \\
\text { words } \\
\%\end{array}$ \\
\hline 11475 & 7655 & 3820 & $66.7 \%$ & $33.3 \%$ & 681 & $8.9 \%$ \\
\hline
\end{tabular}

\section{Discussion}

This study investigates the effect of Saudi EFL post-observation conferences on teachers' professional growth through assessing teachers' reflection. The findings show that the POCs cannot be considered reflection-enhancing tools in the Saudi context. In other words, they do not foster teachers' reflection as a key element of teachers' professional development. The data reveals that the supervisors directly evaluate the teachers. Most of the time, the supervisors' practices are judgmental and non-reflective. This is consistent with Coimbra's (2013) and Tracy's (1995) claims. Coimbra (2013) argues that evaluation provides an overall formal assessment of teachers' competence and performance depending on objectives based on pedagogical frameworks. Tracy (1995) identifies that evaluation proves whether teachers meet specific standards with little or no attention paid to their professional development, and as a result, to their reflection. In addition, the transcribed post-observation conferences indicated that the supervisors paid great attention to stating the teachers' strengths and weaknesses and evaluating the performance of the teachers because they are required to prepare evaluative reports on the teachers, whether positively or negatively. However, it is supposed that supervisors should give teachers opportunities to self-evaluate their own teaching practices because this would help them to enhance their reflection. The practices of the supervisors who participated in this study were judgmental and non-reflective. This result is not the same as what most experts are currently calling for. For example, Arikan (2004) points out that the supervisor's feedback should be reflective rather than judgmental. He explains that even though the supervisors' work includes evaluation, they should concentrate on a formative more than a summative evaluation of teachers because the essence of the supervision is to develop teaching practices and improve instructions. Alanazi (2016) asserts that reflection leads teachers to professionally examine and improve their teaching and classroom practices. It enables them to review and investigate what they did in the classroom, implement changes in practices, and then review and investigate again the alternative or enhanced actions. 
Moreover, in most cases, supervisors only tend to direct the teachers to change their practices and follow what the supervisors say. This is not consistent with what has been reported by several other researchers. Furthermore, the supervisors were the ones who described an observed practice, a practical reason for an observed practice, and consequences of an observed practice. However, supervisors should give teachers opportunities to elicit a description of a certain observed behavior because this requires teachers to think critically. As a result, this enhances their reflection, which is considered an important component of their professional development. This contradicts with the result got from some other researchers. For example, AlAbri (2011) highlights that an opportunity should be provided to teachers, and they should feel free to reflect upon their practices, and the help offered by supervisors can involve occasional probing questions or just comments. Teachers should be the ones who describe an observed action whereas supervisors should only build on those descriptions to make teachers think critically about what happened.

In addition, the findings identify that the main function Reflection-enhancing elicit occurs in only 118 examples, compared to the main function Evaluate that appears in 451 utterances, which is the most frequent category that happens. This means that the supervisors spend most of the time evaluating and commenting on the teachers' behaviors. However, teachers have to be aware of their tacit beliefs that underlie and direct their practices, and they should articulate their assumptions if they want to be reflective. Moreover, teachers should critically examine those beliefs in order to discover whether their teaching practices are effective or need to be improved (Farrell, 2007).

To sum, it has been shown that the supervisors spend most of the time directing and evaluating the teachers' practices. They keep talking about the practices performed inside the classroom, issues related to planning for lessons, the aims and objectives of the units, the strategies and instructional materials used, seating arrangements, and some issues such as the absence issues. In other words, the supervisors' talk does not enhance the teachers' reflection. Furthermore, they are the ones who talk the most. This does not help in fostering teachers' reflection and, consequently, contributing to their professional development. The teachers should reflect on their practices and the supervisors should take the role of guiding them to do so, and, as a result, the teachers will talk more; however, this did not happen. According to Stoller (1996), supervisors should listen more and talk less in order to help teachers to actively participate in the supervisory process. In other words, if supervisors are talking much of the time, teachers will not find time to talk and express themselves. He claims that enough time should be given to teachers by supervisors to be able to reflect on their practices. Furthermore, he proposes that supervisors should support teachers to become capable of helping themselves.

\section{Conclusion}

This study discusses the analysis of the 20 recorded post-observation conferences conducted by female Saudi EFL supervisors and teachers using the functional and the thematic analytic systems. The findings revealed that the post-observation conferences cannot be reflection-enhancing because of many reasons. The supervisors were talking more than the teachers during those meetings. Moreover, the supervisors were found to be mostly asking nonreflection-enhancing questions. In addition, this result was recognized because of the rarity of the occurrence of post-observation conferences in Saudi schools. Therefore, to make post- 
observation conferences reflection-enhancing, several recommendations have arisen in this study. These are:

- Supervisors need to provide teachers with time and opportunities to talk more to be able to critically think and reflect on their teaching practices.

- Supervisors need to be trained about reflection and reflection-enhancing strategies.

- Supervisors should seriously support teachers to develop professionally.

- Supervisors should avoid taking on the role of inspectors.

- In Saudi Arabia, the number of teachers being supervised should be reconsidered. As noted, each supervisor should observe 60 teachers during the whole school year. Therefore, teachers cannot be reflective practitioners because supervisors do not have enough time to conduct more post-observation conferences with the same teachers.

- Training sessions for supervisors and teachers should be set in order to know how to be reflective. Such sessions can be included in pre-service teacher education programs.

- Supervisors may be provided with a guide on how to foster teachers' reflection through conducting appropriate supervision and teachers should be enlightened about this guide.

Acknowledgments: The author would like to thank Deanship of Scientific Research at Majmaah University for supporting this work under Project Number No. R-2021-179.

\section{About the author:}

Dr. Farah Nasser Algraini is an assistant professor of Applied Linguistics at the English Language Department, College of Humanities and Sciences at Hotat Sudair, Majmaah University, Saudi Arabia. Her research interests are in the areas of teacher education, teacher cognition, cognitive and metacognitive learning strategies, and second language acquisition and learning. ORCID: htps://orcid.org/0000-0002-0670-1575

\section{References}

Abednia, A., Hovassapian, A., Teimournezhad, S., \& Ganbari, N. (2013). Reflective journal writing: Exploring in service EFL teachers' perceptions. System, 41(3), 503-514. https://doi:10.1016/j.system.2013.05.003

Al-Abri, F. S. M. (2011). Assessing reflection in EFL supervision feedback conferences, (Unpublished Master's thesis). Sultan Qaboos University, Oman.

Alanazi, M. (2016). An investigation of developing teachers' understanding of using dialogic approach in Saudi primary mathematics classrooms, (Doctoral dissertation). The University of Manchester, Manchester, England.

Almazrawi, G. (2014). Exploring the reflective practice among Saudi female in-service teachers, (Doctoral dissertation). Boise State University, Boise, Idaho.

Alrumaih, B. (2016). Developing supervision: A study on improvement reflection in pre-service teachers in KSM university, (Doctoral dissertation). University of East Anglia, England.

Arikan, A. (2004). Questions to ask in post-observation conferences for a reflective practice. Paper presented at The Joint International ELT Conference Turkey.

Artstein, R., \& Poesio, M. (2008). Inter-coder agreement for computational linguistics. Computational Linguistics, 34(4), 555-596. https://doi:10.1162/coli.07-034-r2

Beach, D. M., \& Reinhartz, J. (2000). Supervisory leadership: Focus on instruction. Boston: Allyn and Bacon.

Bengtsson, J. (1995). What is reflection? On reflection in the teaching profession and teacher 
education. Teachers and Teaching: theory and practice, 1(1), 23-32.

Coimbra, M. (2013). Supervision and evaluation: Teachers' perspectives. International Journal of Humanities and Social Science, 3(5), 65-71.

Dickson, A. (2011). The state of supervision of teaching and learning in public junior high schools in Ghana: A case study of selected junior high schools in Sekyere east district of Ashanti region (Unpublished Master's thesis). KNUSTSpace. Available at http://hdl.handle.net/123456789/4048

Eady, C. K., \& Zepeda, S. J. (2007). Evaluation, supervision, and staff development under mandated reform: The perceptions and practices of rural middle school principals. The Rural Educator, 28(2), 1-7.

El-Okda, M. (1997). Functional and content analysis of ELT supervision feedback reports. Journal of Educational Sciences, Institute of Educational Studies, Cairo University, 12, 1-19.

El-Okda, M. (2008). Reflection in a moodle supported practicum for Omani EFL student teachers (Unpublished manuscript). Educational Sciences, Cairo University, Eygpt.

Farrell, T. S. C. (2007). Reflective language teaching: From research to practice. London: Continuum.

Feiman-Nemser, S., \& Floden, R. (1986). The cultures of teaching. In M. C. Wittrock (Ed.), Handbook of research on teaching (pp. 505- 525). New York: Macmillan.

Gebhard, J. G. (1990). The supervision of second and foreign language teachers. ERIC Digest, ERIC Clearinghouse on Language and Linguistics (EDO-FL-90-06). Washington, D.C.: Center for Applied Linguistics. Retrieved from https://files.eric.ed.gov/fulltext/ED324971.pdf

Gwyn-Paquette, C. (2001). Supervisory conversations: A key to reflective experimentation by pre- service teachers. Journal of Teaching and Learning, 1(2), 16-31.

Hismanoglu, M. (2010). Effective professional development strategies of English language teachers. Procedia - Social and Behavioral Sciences, 2(2), 990-995. https://doi:10.1016/j.sbspro.2010.03.139

Hismanoglu, M., \& Hismanoglu, S. (2010). English language teachers' perceptions of educational supervision in relation of their professional development: A case study of Northern Cyprus. Novitas-ROYAL (Research on Youth and Language), 4(1), 16-34. Retrieved from http://www.novitasroyal.org/Vol_4_1/hismanoglu.pdf

Kutsyuruba, B. (2003). Instructional supervision: Perceptions of Canadian and Ukrainian beginning high-school teachers (Unpublished Master's thesis). University of Saskatchewan, Canada. Retrieved from http://www.collectionscanada.gc.ca/obj/s4/f2/dsk3/SSU/TC-SSU-09052003134303.pdfL

oughran, J. J. (2002). Effective reflective practice: In search of meaning in learning about teaching. Journal of Teacher Education, 53(1), 33-43. https://doi:10.1177/0022487102053001004

Mandell, E. D. (2006). Supervisory practices and their effect on teacher's professional growth, (Unpublished Doctoral dissertation). University of Pittsburgh, Pennsylvania, USA. Retrieved from http://dscholarship.pitt.edu/6716/1/MandellEdwardDissertationMarch2006.pdf

Orland-Barak, L., \& Klein, S. (2005). The expressed and the realized: Mentors' representations of a mentoring conversation and its realization in practice. Teaching and Teacher Education, 21(4), 379-402. https://doi:10.1016/j.tate.2004.05.003 
Pawlas, G. E., \& Oliva, P. E. (2008). Supervision for today's schools (8th ed.). Hoboken, NJ: John Wiley \& Sons, Inc.

Shotte, G. (2008). Reflective teaching: Some reflections. Middlesex University Occasional Papers in Educational and Lifelong Learning, 2(1), 5-23.

Shukri, N. (2014). Exploring female teachers' perceptions toward peer observation: Issues and challenges in the Arab context. Arab World English Journal, 5(2), 153-166. Retrieved from https://www.academia.edu/14434019/Exploring_Female_Teachers_Perceptions towards _Teacher_Observation_Issues_and_Challenges_in_the_Arab_Context

Sibahi, R. (2015). Exploring reflective practice among collage EFL teachers in Saudi Arabia. Arab World English Journal, 6(2), 337-351. https://dx.doi.org/10.24093/awej/vol6no2.26

Stoller, F. L. (1996). Teacher supervision: Moving towards an interactive approach. English Teaching Forum, 34(2), 2-9. Available at https://americanenglish.state.gov/files/ae/resource_files/03-41-4-c.pdf

Susoy, Z. (2015). Watch your teaching: A reflection strategy for EFL pre-service teachers through video recordings. Procedia - Social and Behavioral Sciences, 19,163-171. https://doi:10.1016/j.sbspro.2015.07.501

Tracy, S. J. (1995). How historical concepts of supervision relate to supervisory practices today. The Clearing House, 68(5), 320-25.

Vásquez, C. (2004). Very carefully managed: Advice and suggestions in post-observation meetings. Linguistics and Education, 15 (1-2), 33-58. https://doi.org/10.1016/j.linged.2004.10.004

Waring, H. Z. (2013). Two mentor practices that generate teacher reflection without explicit solicitations: Some preliminary considerations. RELC Journal, 44(1), 103-119.

Zepeda, S. J. (2012). Instructional supervision: Applying tools and concepts (3rd ed.). Larchmont, NY: Eye on Education. 